\title{
DIÁLOGOS ENTRE O DIREITO E A LITERATURA: \\ ARQUIPÉLAGOS A DESCOBRIR .
}

\author{
UMA PROPOSTA DE APROXIMAÇÃO ENTRE A PRÁTICA E A TEORIA DOS DIREITOS \\ HUMANOS FUNDAMENTAIS A PARTIR DO CONTO DA ILHA DESCONHECIDA
}

\section{Melina Girardi Fachin}

Formação e Vínculo Institucional: Acadêmica do $5^{\circ}$ ano da Faculdade de Direito da Universidade Federal do Paraná.

e-mail: melinafachin@onda.com.br

RESUMO: O artigo parte da narrativa de Saramago, intitulada "Conto da ilha desconhecida", para discutir os direitos humanos, em especial o hiato que há entre a sua construção teórica e a sua efetivação. O recurso à literatura é uma das possibilidades de que dispõe o discurso jurídico para tentar responder aos problemas que cotidianamente the são colocados e que, tradicionalmente, buscou-se solucionar através da gramática da ciência positivista do direito, como se esta fosse capaz de subsumir toda a complexidade social. Especificamente em relação à construção teórica e efetivação dos direitos humanos, entende-se que as tramas que lá se tecem podem ser mais bem trabalhadas e gerar um tecido mais justo, se levarmos em conta a narrativa literária porque mais complexa, atenta e aberta aos antagonismos e paradoxos que lhe são constitutivos.

PALAVRAS-CHAVE: Direitos humanos; direitos fundamentais; literatura; Saramago. 


\section{NOTAS INTRODUTÓRIAS}

A complexidade contemporânea do real, sobretudo no que tange à seara dos direitos humanos, revelou a incapacidade, ao menos no plano prático, da teoria jurídica tradicional em responder às demandas sociais que ecoam nas vozes das classes menos favorecidas, alijadas do processo de desenvolvimento.

O direito como objeto da ciência jurídica centrada no positivismo jurídico de matriz kelseniana, foi reduzido à gramática do seu significado sintático e semântico, articulado no enunciado de suas normas, as quais, nesta perspectiva, significavam todo o direito. Para além do elemento normativo não haveria direito, reducionismo cuja gravidade se intensifica no campo dos direitos humanos e fundamentais.

Contemporaneamente, o descompasso existente entre a teoria dos direitos humanos - positivada em declarações internacionais e reafirmada na maioria das cartas constitucionais hodiernas - e sua prática, ou melhor, a ausência dela escancarada nas duras condições de vida dos brasileiros que vivem abaixo da linha da pobreza ${ }^{1}$ - revela a insuficiência da dogmática positivista que se mostra incapaz de responder às demandas postas ao direito.

Diante deste quadro, faz-se imperiosa uma outra teoria dos direitos humanos e fundamentais que responda justa e democraticamente às demandas da comunidade a qual se aplica, isto é, que comprometa o discurso jurídico dos direitos humanos e fundamentais à sua efetivação.

A viragem para esta outra conformação, fundamentação e aplicação dos direitos humanos e fundamentais pressupõe um paradigma crítico, o qual encontra

\footnotetext{
${ }^{1}$ A ordem jurídica do terceiro milênio deve ser capaz de responder satisfatoriamente, não apenas através da consolidação constitucional dos princípios fundamentais, mas por meio da afirmação prática desses direitos, aos 47,2\% de brasileiros que ainda vivem abaixo de um padrão mínimo de higiene e, conseqüentemente, de humanidade. Ainda, de acordo com o IBGE apenas 52,8\% dos brasileiros possuem alguma espécie de fossa séptica ou esgoto. Os dados são mais alarmantes em regiões como o Nordeste onde pouco mais de $20 \%$ das residências possui. Pesquisa Nacional por amostra de domicílios 1999 (CD-ROM). Microdados. Rio de Janeiro: IBGE, 2002.
} 
reflexo em uma postura desconstrutivista ${ }^{2}$ perante o direito - acusando seus limites, incompletudes e contradições - com uma perspectiva reconstrutivista que o afirma não sem assumir o seu caráter contingente.

Esse novo olhar apenas pode abrolhar sob uma miragem crítica e inovadora que contenha outras possibilidades teóricas, especialmente críticas em relação ao papel do ordenamento na salvaguarda dos direitos humanos e fundamentais. É justamente neste influxo que emerge a literatura como uma dessas possibilidades de análise no campo dos direitos humanos, como emancipação destes frente à racionalidade jurídica tradicional.

Martha Nussbaum ratifica a possibilidade libertadora do recurso à literatura quando afirma que:

Pode haver algumas visões do mundo e de como nele se deveria viver - visões que, especialmente, enfatizam a sua surpreendente diversidade, sua complexidade e mistério, sua defeituosa e imperfeita beleza e que não podem ser completa e adequadamente colocadas na linguagem da prosa filosófica convencional, um estilo marcadamente monótono e carente em imaginação, mas somente em linguagem e formas mais complexas, mais alusivas e mais atentas ao específico. ${ }^{3}$

Neste sentido, a pesquisa que aqui se põe pretende analisar o fosso abissal entre a teoria e a prática dos direitos humanos e fundamentais a partir da obra de José Saramago, intitulada "Conto da ilha desconhecida".

Portanto, não se poderia começar este trabalho senão com a indagação do homem do Conto da Ilha Desconhecida de Saramago": "E a ilha desconhecida, perguntou o homem do leme, A ilha desconhecida não passa de uma idéia da tua cabeça, os geógrafos do rei foram ver nos mapas e declararam que ilhas por conhecer é coisa que se acabou desde há muito tempo".

2 "The fact that law is deconstructible is no bad news. We may even see in this a stroke of luck for politics, for all historical progress. But the paradox that I'd like to submit for discussion is the following: it is this deconstructible structure of law (droit), or if you prefer of justice as droit, that also insures the possibility of deconstruction. Justice in itself, if such a thing exists, outside or beyond law, is not deconstructible. Deconstruction is justice. It is perhaps because law (droit) (which I will consistently try to distinguish from justice) is constructible, in a sense that goes beyond this opposition between convention and nature, it is perhaps insofar as it goes beyond this opposition that it is constructible and so deconstructible and, what's more, that it makes deconstruction possible, or at least the practice of a deconstruction that, fundamentally, always leads to questions of droit. 1. The deconstructibility of law (droit) makes deconstruction possible. 2. The undeconstructibility of justice also makes deconstruction possible, indeed is inseparable from it. 3 . The result: deconstruction takes place in the interval that separates the undeconstructibility of justice from the deconstructibility of droit (authority, legitimacy, and so on)." DERRIDA, J. Force of law. Cardozo Law Review. Vol 11. July/Aug. 1990. p. 943-944.

${ }^{3}$ NUSSBAUM, M. Love's Knowledge. New York and Oxford: Oxford University Press, 1990, p. 03. 
O homem, nutrido pelo seu sonho de liberdade enxerga no barco do rei o instrumental necessário para a efetivação da sua vontade de ir em busca da ilha desconhecida. No entanto, ao mesmo tempo em que trilha seu caminho em direção à ilha desconhecida, ou quiçá, inexistente, descobre esta também dentro de si como algo que jazia dormente e, então, desflorou.

O homem do leme (re)afirma o objeto metodológico desta pesquisa, qual seja, a cumplicidade entre o direito e a literatura. A reflexão que ora se propõe, objetiva mostrar que uma nova maneira de pensar o direito e os direitos humanos pode levar em conta a narrativa literária, na qual as tramas que se tecem revelam o necessário nó político-ético da trama jurídica.

Bem como o homem da história de Saramago que com o barco fornecido pelo rei traçou uma ponte entre seu sonho e a efetivação deste - buscar a ilha desconhecida - a reflexão delinear-se-á acerca da busca de mecanismos efetivos de aproximação do discurso teórico e da proteção efetiva dos direitos humanos fundamentais (nossa ilha desconhecida) ${ }^{5}$. É este itinerário que singelamente objetivamos traçar no presente trabalho, rompendo com a monotonia destas travessias que não encampam a luta e atêm-se ao conformismo.

Para tanto, o trabalho equilibra-se sob uma base dual a qual, ao seu turno, se assenta em diversos alicerces com objetivo de melhor explorar a temática. $\mathrm{O}$ primeiro pilar do artigo versa sobre a possibilidade de um direito (e de direitos) cuja narrativa, a exemplo da narrativa literária, se possa desconstruir apontando as suas incompletudes e insuficiências. Na segunda e derradeira parte, por meio do conto de Saramago, buscamos compreender os direitos humanos e os direitos fundamentais a partir de uma narrativa jurídica transformadora que, ao invés de reproduzir e conservar os velhos e insuficientes discursos jurídicos os desconstrua para, então, reconstruir o direito em bases radicalmente comprometidas com a democracia e a justiça material.

Buscar a aproximação do discurso teórico e da prática efetiva dos direitos humanos e fundamentais é, quiçá, navegar contra a maré da teoria jurídica

\footnotetext{
${ }^{4}$ SARAMAGO, J. O Conto da Ilha Desconhecida. São Paulo: Cia das Letras, s.d.

${ }^{5}$ A ilha desconhecida subsiste tanto no coração daquele homem e também nos arquipélagos da vida, o que, de fato, a torna uma busca incessante; a nossa ilha desconhecida - mecanismos de aplicação prática do discurso jurídico dos direitos humanos - é de igual maneira procura constante, dentro e fora do ordenamento jurídico.
} 
tradicional e dominante; é, todavia, a assunção do comprometimento social do Direito contra a acachapante e perversa racionalidade da exclusão social.

\section{O CARÁTER EMANCIPADOR DO DIREITO LIDO PELOS OLHOS}

\section{DA LITERATURA ${ }^{6}$}

O diálogo salutar entre o discurso literário e a narrativa jurídica pode ser concebido de diversos modos. ${ }^{7}$ Tradicionalmente, nas incomuns interseções entre essas duas searas, o aporte literário é explorado, não raro, em sua superficialidade para a construção de metáforas, formando uma espécie de direito literário. Através deste pensamento o ideário que subjaz a interligação do direito e da literatura resta latente e intocado.

O estudo das maneiras de conexão entre estes dois discursos não é discussão relegada ao plano abstrato. Consoante assevera Jacques Derrida: "under the pretext of fiction, literature must be able to say anything; in other words, it is inseparable from the human rights, from the freedom of speech, etc."

A análise das diversas formas de pensar o direito a partir da literatura é, em realidade, a apreciação de modos plurais e porosos de incidência do fenômeno jurídico. Não se trata de acondicionar a literatura no direito, reduzindo-a aos saberes espraiados nos manuais de ensino jurídico ou de exegese jurisprudencial, os quais compõem o que tradicionalmente se chama de doutrina ou literatura jurídica.

${ }^{6}$ Neste momento do trabalho, faz-se mister alerta que na discussão que ora se propõe restam algumas interrogações para as quais nunca se encaixarão pontos finais, a exemplo do sentido ontológico dos dois elementos deste enlace: direito e literatura. Não há enunciado plausível de enclausurar tais significantes tendo em vista a inesgotável força criativa dos fatos e das mentes que os movem. Para os efeitos desta reflexão, direito e literatura - e conseqüentemente seus espaços de interseção - serão apreendidos em sua narrativa emancipatória. Explique-se que esta via é assim apontada sem a exclusão de outras sendas, mas, em nosso ver, tão só o caráter emancipatório pode abrir este diálogo interdisciplinar, crítico e construtivo.

${ }^{7}$ Neste diapasão, Thomas Morawetz (MORAWETZ, T. Law and Literature. In: PATERSON, D. A Companion to Philosophy of Law and Legal Theory. USA: Blackwell, 1999.) nos apresenta formas diversas de pensar sobre direito e literatura: o direito na literatura (law in literature), o direito como literatura (law as literature), direito da literatura (law of literature) e literatura e mudanças jurídicas (literature and legal reforms). Consoante a temática de fundo, esta classificação não se apresenta como taxativa e estanque. Todavia, não nos ateremos à sua análise, em que pese bem demonstrarem as intrincadas redes que a literatura e o direito formam, tendo em vista as limitações materiais do presente estudo. 
As abstrações que deste diálogo germinam apresentam efeitos práticos. A teoria jurídica tradicional apresenta profundas variações quando mirada através das lentes lúdicas literárias. Destarte, obrada esta mudança de referencial, é factível que haja uma mudança de racionalidade no discurso jurídico tradicional pretensamente hermético e autopoiético ${ }^{9}$.

Assim, em conformidade com as lições de Jacques Derrida podemos assegurar que:

(...) not only does literature simultaneously depend on and interrogate laws, but the law the continual subject of narratives - can only be understood as a self-contraditory, lacking in pure essence, and structurally related to what Derrida terms différance, in its unmetaphysical sense, literature ${ }^{10}$.

Neste diapasão, Martha Nussbaum ensina que "la narrativa y la imaginación literaria no sólo se oponen a la argumentación racional, sino que pueden aportarle ingredientes esenciales"11. Prossegue a autora, justificando sua opção pelo recurso literário: "Defiendo la imaginación literaria porque me parece un ingrediente esencial de una postura ética que nos insta a interesarnos en el bienestar de personas cuyas vidas estan distantes de la nuestra"12.

Esta ordem de idéias já se fazia presente no pensamento filosófico clássico, pois, segundo Aristóteles ${ }^{13}$, a arte literária é "mais filosófica" que a própria história. Esta se limita a narrar o ocorrido enquanto aquela descreve o que poderia ocorrer.

8 "sob o pretexto de ficção, a literatura deve ser capaz de dizer alguma coisa, em outras palavras, ela é inseparável dos direitos humanos, da liberdade de expressão, etc." (Tradução Livre).DERRIDA, Jacques. Remarks on deconstruction and pragmatism. In: MOUFFE, Chantal. Pragmatism and deconstruction. New York and London : Routledge, 1996, p. 80.

${ }^{9}$ De acordo com a teoria luhmaniana o sistema social é composto por vários subsistemas que nascem de um processo de diferenciação funcional. Cada um destes subsistemas funciona, segundo o autor, autopoieticamente e o seu entorno não influenciaria as modificações daquele sistema. As alterações determinadas no interior do sistema não ocorreriam de acordo com a racionalidade do entorno. Gera-se, assim, uma concepção positiva e acabada do subsistema jurídico. In: LUHMAN, N.

${ }^{10}$ Acts of Literature. P. 182.

11 "A narrativa e a imaginação literária não apenas se opõe a argumentação racional, mas também Ihe aportam ingredientes essenciais"(Tradução Livre). In: NUSSBAUM, M. Justicia Poética. Santiago do Chile: Andrés Bello, 1997. p. 15.

12 "Defendo a imaginação literária precisamente porque me parece um ingrediente essencial de uma postura ética que nos insta a interessarmos no bem-estar das pessoas cujas vidas estão distantes da nossa." (Tradução Livre)Id. p. 18.

${ }^{13}$ Aristóteles. Poética 9. 
Enquanto a disciplina histórica centra-se em ações passadas concretas, a literatura se centra nas ações possíveis.

A articulação do discurso jurídico com a narrativa literária é apropriada, uma vez que insta a abertura da ciência jurídica. Para François Ost, "entre le droit et le récit, des rapports se nouent et se dénouent qui semblent hésiter entre dérision et ideal. Et voilà le droit ébranlé dans ses certitudes dogmatiques et reconduit aux interrogations essentielles..."14

São dois interstícios que se fundam: por um lado, o direito conecta-se à interdisciplinaridade e ao diálogo com outros ramos e outras formas de saber; por outro lado, o fenômeno jurídico se articula com as demandas sociais, seu verdadeiro escopo, libertando-se, assim, das amarras positivas.

Portanto, "la lectura de novelas no nos dirá todo sobre la justicia social, pero puede ser un puente hacia una visión de la justicia y hacia la realización social de esa visión"15.

Por meio desta racionalidade, o direito passa a enxergar os sujeitos não mais como "membros de uma massa anônima e indiferenciada", destinatária dos textos legais, mas sim como "seres humanos singulares e individuais" ${ }^{16}$. Isto porque, conforme afirma Nussbaum:

a novela narra una historia. Al hacerlo, induce al lector a interesarse por los personajes, a participar de sus proyectos, temores e esperanzas, a compartir sus intentos de desentrañar los misterios y perplejidades de sus vidas. La participación del lector se explicita en muchos puntos de la narración. Y los lectores comprenden que en cierto modo se trata de su propia historia, pues muestra posibilidades de elección que en cierto sentido también son las suyas, aunque las circunstancias concretas varíen enormemente. El lector evalúa e interpreta con actitud critica pero afectuosa, pues el texto lo retrata como un agente social responsable de crear un mundo que puedo parecerse o no al mundo que hay en esas páginas, un agente que en la vida debe entablar una relación emocional y practica con los problemas de la clase obrera y la conducción de los gerentes y dirigentes. Al imaginar cosas

${ }^{14}$ Raconter la Loi. p. 7.

15 "A leitura de textos literários não nos dirá tudo sobre a justiça social, porém pode ser uma ponte para a visão de justiça e para a realização social desta visão".(Tradução Livre). In: NUSSBAUM, M. Ibid. p. 38.

${ }^{16}$ Woodson v. North Carolina, 428 U.S. 280, 304 (1976). 
que en verdad no existen, la novela, como ella misma lo manifiesta, no es "improductiva", pues ayuda a sus lectores a reconocer su propio mundo y a escoger más reflexivamente. ${ }^{17}$

É justamente esta possibilidade de libertação do fenômeno jurídico das amarras positivistas que o seguram distante da realidade social que o discurso literário nos permite. Neste diapasão, afiança Ost: alors que la littérature libère des possibles, le droit codifié la realité (...) Tel est bien le travail de la littérature: bousculer les conventions, suspendre nous certitudes, libérer des possibles dégager l'espace ou libérer le temps des utopies créatrices. ${ }^{18}$

A interlocução com o elemento lúdico torna o tecido jurídico maleável à percepção social sem retirar-lhe o enfoque racional próprio do pensamento científico. Dotada de imaginação a razão jurídica se torna benigna, sem aquela esta recai no dogmatismo frio e cruel da lei.

O pretenso viés cientificista de busca da "razão" e da "verdade" é que alicerça as resistências de grande parte da doutrina jurídica ao recurso literário ${ }^{19}$. Todavia, o discurso jurídico legal, ou tradicional, não possui respaldo fático que o torne porta-voz desta pretensa verdade, já que não espelha a vida concreta dos sujeitos que dela necessitam.

Segundo apregoa Ingo Sarlet ${ }^{20}$, estamos vivendo um mal-estar constitucional, já que o Estado Democrático de Direito não se efetivou para grande

17 "O texto literário narra una historia. Ao fazê-lo, induz o leitor a se interessar pelos personagens, a participar de sus projetos, temores e esperanças, a compartilhar seus intentos de desenterrar os mistérios e perplexidades de suas vidas. A participação do leitor se explicita em muitos pontos da narração. E os leitores compreendem que de certo modo se trata de sua própria história, pois mostra possibilidades de eleição que em certo sentido também são as suas, ainda que as circunstâncias concretas variem enormemente. O leitor avalia e interpreta com atitude crítica, porém afetuosa, pois o texto o retrata como um agente social responsável de criar um mundo que pode se parecer ou não com o mundo que há nessas páginas, um agente que na vida deve encampar una relação emocional e prática com os problemas da classe trabalhadora e a condução dos gerentes e dirigentes. Ao imaginar coisas que na verdade não existem, o conto, como ele mesmo se manifesta, não é "improdutivo", pois ajuda seus leitores a reconhecer seu próprio mundo e a escolher mais reflexivamente. (Tradução Livre). In: NUSSBAUM, M. Ibid. p. 60.

Neste influxo, François Ost aponta uma diferença estrutural entre o discurso jurídico e a narrativa literária: "alors que celui-là (le droit) se decline dans le registre de la généralité et de l'abstraction (la loi, dit-on, est générale et abstraite), celle-ci (la literature) se déploie dans le particulier et le concret." In: Raconter la Loi. p. 15.

${ }^{18}$ OST, F. Raconter la Loi. p. 10.

19 "Lê droit ne se contente pás de defende dês positions instituées, mais exerce également des fonctions instituantes - ce qui suppose création imaginaire de significations sociales-historiques nouvelles et déconstrution dês significations instituées qui leur font obstacle. À l'inverse, et simetriquement, la littérature ne se contente pás d'oeuvrer sur lê versant instituant de l'imaginaire, il lui revient aussi de s'appuyer sur sés formes instituées." In: OST, F. Raconter la Loi. p. 15.

20 SARLET, I. W. SARLET, I. W. A Eficácia dos direitos fundamentais. Porto Alegre: Livraria do Advogado, 1998. 
parte da população. Ao menos para os 24,3 milhões de brasileiros que vivem abaixo da linha da pobreza ${ }^{21}$, a constituição brasileira de 1988 - e os princípios implícitos e explícitos dela derivados - não saíram do papel.

É neste influxo que Richard Posner ressalta este salutar diálogo entre direito e literature, tendo em vista a acusação literária das injustiças legais"22. "show how a lawyer's knowledge can enrich our understanding of such fiction and how a critic's knowledge of such fiction can enrich our understanding of law"23.

Destarte, o escopo racional da ciência jurídica também não subsiste como elemento refutador da interlocução com a literatura. Em primeiro lugar, porque a ficção não está apenas no discurso literário, mas também, na teoria jurídica, conforme nos aponta Ost: "les fictions dont regorge le droit (l'extra-territorialité des hôtels diplomatiques, par exemple)"24. Em segundo lugar, a teorização jurídica soidisant acrítica e neutral revela percepção enodoada do real marcada por uma ideologia subjacente.

Tanto o direito quanto a literatura são produtos da subjetividade humana. Portanto, ambos possuem uma vocação emocional irrefreável. O direito é, do mesmo modo que a narrativa literária, um dos possíveis discursos sobre o real. Nesta singra, atestigua Martha Nussbaum que "la novela no nos exhorta a desechar la razón, sino a llegar a ella bajo la luz de la fantasía, entendida como una facultad creativa e veraz."25

A objeção da narrativa literária encontra assento no fato de estar ontologicamente imbricada com manifestações emocionais ${ }^{26}$. Assim, partindo-se do paradigma neutro e cartesiano, que dissocia a razão da emoção como critério de validade do pensamento cientifico, o discurso literário não teria espaço dentro do

${ }^{21}$ Dado obtido no site: http://www.andes.org.br/imprensa/ultimas/contatoview.asp?key=3075.

22 "The Literary Indictment of Legal Injustice". É o título do $5^{\circ}$ capítulo da obra: POSNER, R. Law and Literature. Massachusetts: Harvard University Press, 1998.p. 148.

23 "mostrar como o conhecimento de um advogado pode enriquecer a compreensão da ficção e como o conhecimento de um crítico literário pode enriquecer o entendimento do direito." Id.

${ }^{24}$ OST, F. Raconter la Loi. p. 35.

25 "O texto literário não nos leva a descartar a razão, apenas aproximar-se dela sob a luz da fantasia, entendida como faculdade criativa e veraz".(Tradução Livre). In: NUSSBAUM, M. Ibid. p. 74.

26 "Las emociones no solo constituyen respuestas probables ante el contenido de muchas obras literarias, sino que son inherentes a su misma estructura, como maneras en que las formas literarias solicitan atención". In: NUSSBAUM, M. Ibid. p. 85. 
meio acético do direito. Refutando tais idéias, Richard Posner avalia a contribuição que a emoção poderia aportar à racionalidade pública e ao direito:

?Es posible suponer que las personas son racionales sólo o principalmente cuando realizan transacciones en los mercados y cuando no realizan otras actividades de la vida, tales como el matrimonio, el litigio, el delito, la discriminación y el ocultamiento de información? (...) Pero muchos lectores sin duda considerarán intuitivamente que estas elecciones (...) se encuentran en el área donde las decisiones son emocionales, más que racionales. ${ }^{27}$

O sensorial emotivo aporta no contexto jurídico como elemento diferencial na prática do direito. As emoções preocupam-se com os indivíduos, capturando a vida em todas as suas vicissitudes e nuances. ${ }^{28}$ Nesta via também singram os ensinamentos de Nussbaum ao dizer que "es la emcoción del espectador juicioso, la emoción que las obras literarias forjan em sus lectores, que aprendem lo que es sentir emoción por 'una masa anônima e indiferenciada' sino por el 'ser humano individual y singular'"29.

O direito - visto sob as lentes lúdicas literárias - enxerga a vida concreta de cada sujeito ${ }^{30}$ opondo-se a "un enfoque seudo científico de la economía, y también a su insensible aplicación sin respecto por las historias que se narran dentro de un contexto histórico concreto"31. A releitura do direito através do olhar literário se refere a um posicionamento crítico da herança jurídica tradicionalista.

A literatura apresa a biografia de cada sujeito que por ela passa, assim, nos leva a captar cada vida como individual e singular. Este exercício hermenêutico mostra-se deveras importante em um país com uma conjuntura social como o Brasil, pois é necessário para o abrandamento do fosso social. A compreensão literária singra pelo iter da igualdade social já que podemos, através dela, em um vívido e

${ }^{27}$ POSNER, R. The Economics of Justice. p. 2.

${ }^{28}$ Necessária advertência de Marta Nussbaum ao admitir que "no todas lãs emociones son buenas guias. Para ser uma buena guia la emoción debe ante de todo estar informada por uma visión verdadera de lo que sucede: los datos Del caso, su significado para los actores y todas las dimensiones de su sentido o importancia que puedan resultar elusivas o distorsionadas en la consciencia de los actos."In: Ibid. P. 109.

29 "É a emoção do espectador sensato, a emoção que as obras literárias forjam em seus leitores, que apreendem o que é sentir não por 'uma massa anônima e indiferenciada', mas sim pelo 'ser humano individual e singular'". In: NUSSBAUM, M. Ibid. p.114.

3030 Referência ao quarto paradigma jus-filosófico da vida concreta de cada sujeito. Ver: MATURANA, H. \& VARELA, F. A árvore do conhecimento: as bases biológicas da compreensão humana. São Paulo: Palas Athena, 2001

31 “...um enfoque pseudocientífico da economia e também sua insensível aplicação sem respeito pelas histórias que se narram dentro de um contexto histórico concreto". In: NUSSBAUM, M. Ibid. p. 76. 
profundo exercício de alteridade, "imaginar el dolor de outra persona y preguntar por su significación, es um modo poderoso de apreender acerca de la realidad humana y de adquirir uma motivación para modificarla"32.

Assim, a seara jurídica - e suas interpretações (dela e que dela decorrem) aponta alterações ideológicas e substanciais quando mirada através do discurso literário. Desta maneira, a interlocução aqui proposta abotoa no campo das teorizações e o transcende apontando efeitos e mudanças práticas. ${ }^{33}$

Nesta toada, François Ost afirma que "la littérature contribue directment à la formulation et à l'élucidation des principales questions relatives à la justice, à la loi et au pouvoir"34. Desta religação ontológica com a justiça - não tomada em sentido metafísico, mas a justiça no caso concreto - abrolha o escopo prático deste diálogo.

Partindo desta ordem de idéias, a literatura seria um espelho invertido da prática que abrolha do discurso jurídico. Pois cabe a ela, segundo Ost, "penser la justice contre elle-même: mettre à distance la justice comme instituition (toujours tentée par l'enfermement dans l'ideologie), pour libérer la justice comme valeur er rappeler ainsi l'institution à as réelle vocation"35.

Paradoxalmente, a literatura, haja vista sua forte carga imaginária, passa a ser espelho da realidade. A literatura, ao contrário do direito, não se propõe a deturpar a realidade, mas sim a apreende e a recria. O discurso jurídico é também ficção, um imaginário descritivo a partir de uma concepção e apreensão do real. Assim, a prática que daí deriva pode guardar, e guarda distância da afirmação teórica e legal.

A narrativa literária e o discurso jurídico são produtos ficcionais, imaginários descritivos a partir de uma concepção e apreensão do real. A literatura, porém, ao

32 “... imaginar a dor de outra pessoa, de participar dela e perguntar seu significado, é um modo poderoso de aprender sobre a realidade humana e de adquirir uma motivação para modifica-la " In: NUSSBAUM, M. Ibid. p. 129.

33 Diametralmente oposta a esta ordem de idéias é a obra de Posner quando afirma, baseando-se em Stanley Fish: " He (Stanley Fish) is empathic that the theory cannot bring us to the happy state. The theory can have no effect on practice. For Fish, every area of human activity is a game that has rigid rules, like chess. You could have a theory about chess - about his origins, its fascination, even how it might be improved by a change in rules. But you could not use the theory in playing chess. When you play chess you play by its rules, not theory's rules. So legal theory, including theories about interpretation, whether they originate in law itself, or in literary theory or practice, or anywhere else, could not be expected to alter the way judges decide cases. Fish argues, because judges play the judging game, which has its own rules." In: POSNER, R. Law and Literature. p. 249.

${ }^{34}$ OST, F. Raconter la Loi. p. 45.

${ }^{35}$ OST, F. Raconter la Loi. p. 18. 
revés do direito, não deturpa a realidade, mas sim a apreende e a recria. Esta consciência não encontra espaço na ciência dogmática e positivista, desta maneira, sob a pretensão de ser o real o direito a deturpa. Equilibrada sob estas premissas, a prática que daí deriva pode guardar, e guarda distância da afirmação teórica e legal.

Este interstício abissal entre o discurso e a prática do direito é, ao menos, suavizado, se admitirmos outras miradas acerca do fenômeno jurídico, a exemplo da releitura jurídica pela via literária. A literatura opera uma refundação basilar nesta concepção jurídica moderna, consoante afirma François Ost

(...) c'est une fonction de conversion fondatrice qu'assume la literature, sans l'avoir nécessairement cherché pour autant: le récit se fait 'foundateur' - comme la plupart de ceux quón étudie dans ce livre - donnant non seulement à penser, mais aussi à valoriser, et biantôt à prescrire.

Ainsi l'exploration de l'envers du décor juridique, qui aura révélé sés fictions et sés constructions em trompe-l'oeil, sés artífices et sés effets de scène, produira-t-elle, du même movement, et un savoir critique des construtions juriqdiques et une amorce de refondation de celles-ci sur fond d'une connaisance élargie des puissances du langage, ainsi que des tours et détours de la raison pratique. ${ }^{36}$

A possibilidade de superação desta distância prática que guarda a ciência jurídica tradicional por meio de uma ponte literária que a aproxime dos sujeitos concretos e da justiça material, é que torna imprescindível que a esta singela reflexão aporte o conjunto de idéias acima exposto.

O desenvolvimento do primeiro pilar do presente trabalho, até aqui levado a efeito, teve esse fim que agora explicita, claramente, o viés adotado, qual seja, uma releitura que se propõe como comprometida, emancipadora e crítica da teoria dos direitos humanos e dos direitos fundamentais - como aqui se busca.

Mais ainda, essa proposta que almeja evidenciar, de um lado, o diálogo entre o direito e a literatura, e de outro, a imperiosa necessidade de superação entre teoria e prática, se projeta, por meio do conto da Ilha Desconhecida, como método e conteúdo emancipatórios no âmbito dos direitos humanos e dos fundamentais.

36 Id. p. 21. 


\section{SARAMAGO DA ILHA DESCONHECIDA REVISITADO: UMA PERSPECTIVA DOS DIREITOS HUMANOS E FUNDAMENTAIS A PARTIR DO CONTO DA ILHA DESCONHECIDA}

Fixadas as bases gerais sobre as quais o diálogo entre o direito e a literatura se articulam na presente reflexão, faz-se necessária certa particularização dos elementos dialógicos. Trava-se, a partir deste momento, a interlocução entre os direitos humanos e fundamentais e 0 Conto da llha Desconhecida ${ }^{37}$ de José Saramago. Duas margens possíveis, banhadas pelo mesmo curso de saberes, a serem vincadas por uma zona de intersecção comum.

Consoante anteriormente asseverado, edifica-se essa ponte dialética, uma vez que buscamos compreender os direitos humanos e os fundamentais desde um embasamento emancipatório que apresenta crítica às narrativas jurídicas até então elaboradas e que se mostraram insuficientes para a efetivação destes.

Especificamente em relação à construção teórica e efetivação dos direitos humanos e fundamentais, entende-se que as tramas que se tecem podem ser mais bem trabalhadas e gerar um tecido mais justo se levarmos em conta a narrativa literária, mais complexa, atenta e aberta aos antagonismos e paradoxos que são lhe constitutivos.

Neste sentido, Saramago assegura que "a literatura sempre tem algo a dizer num mundo como o atual, onde o ser humano é a coisa mais descartável que há. Perdemos o sentido do protesto, o sentido crítico, parece que vivemos no melhor dos mundos possíveis". Assegura ainda que "a globalização econômica é uma nova forma de totalitarismo" e que "a democracia é um ponto de partida e não de chegada". Encerra afirmando que "assistimos a um mundo em extinção"38.

Atentando para tal objetivo, inicialmente faz-se imperiosa a delineação qualitativa do texto de Saramago já que baldrames e alicerce das meditações o seguirão após.

Essa história de perseverança inicia-se quando um homem, alimentado por seu sonho, foi bater à porta das petições do castelo do rei para pedir-lhe um barco. Usualmente, estes requerimentos não ocupam os afazeres da Corte, pois, estavam

\footnotetext{
37 SARAMAGO, J. O Conto da Ilha Desconhecida. São Paulo: Cia das Letras, 1999.

${ }^{38}$ Entrevista extraída do site geocities.yahoo.com.br/ciencia2000_br/caverna.html.
} 
sempre mais ocupados com a porta dos obséquios (que faziam ao rei, ressalva o autor português).

Com o homem em questão, porém, as coisas desde o início já se passaram de modo diverso. Não desistiu, ficou irresignado por três dias e três noites frente à porta até que o rei, em pessoa, abalou-se até o local para tomar ciência da identidade "do intrometido que se havia negado a encaminhar o pedido pelas competentes vias burocráticas"39.

Assim, abrindo a porta das petições vislumbrou-se o rei, fato inédito até então naquele reino, que se dirigiu ao homem com três perguntas ininterruptas: "Que é que queres, Por que foi que não disseste logo o que querias, Pensarás tu que eu não tenho mais nada o que fazer" ${ }^{40}$. O homem respondeu-lhe singelamente: "Dá-me um barco" ${ }^{\prime 1}$.

Destarte, intrigado o rei prosseguiu com as indagações: "E tu para que queres um barco". "Para ir a procura da ilha desconhecida" retrucou o homem. Certo da impossibilidade do pleito o rei lhe redargüiu: "Disparate, já não há ilhas desconhecidas, Estão todas nos mapas". Seguro de seu pedido, ou melhor, de seu sonho, o homem replicou: "Nos mapas estão só as ilhas conhecidas(...) Se eu to pudesse falar dizer (que ilha desconhecida é essa), então não seria desconhecida (...) É impossível que não exista uma ilha desconhecida!”42.

Como monarca preocupado com as possessões do reino, ele inquire a respeito da eventual titularidade desta (im)possível ilha. Contrapõe o homem que ao soberano apenas "interessam as ilhas conhecidas", este, todavia, alega que Ihe "interessam as ilhas desconhecidas quando assim o deixam de ser". Rebate o requerente que "Talvez esta não se deixe conhecer"43.

\footnotetext{
${ }^{39}$ Saramago explana o funcionamento procedimental do atendimento aos requerimentos: "Só quando o ressoar contínuo da aldraba de bronze se tornava, mais do que notório, escandaloso, tirando o sossego da vizinhança (as pessoas começavam a murmurar, Que rei temos nós, que não atende), é que dava ordem ao primeiro-secretário para ir saber o que queria o impetrante, que não havia maneira de se calar. Então o primeirosecretário chamava o segundo secretário, este chamava o terceiro, que mandava o primeiro-ajudante, que por sua vez mandava o segundo, e assim por aí fora até chegar à mulher da limpeza, a qual, não tendo ninguém em que mandar, entreabria a porta das petições e perguntava pela frincha, Que é que tu queres." In: O conto da Ilha Desconhecida. p. 5 e ss.

40 Ibid. p. 15.

41 Id.

42 Ibid. Trecho do diálogo retirado da página 17.

43 Ibid. Trecho do diálogo retirado da página 18.
} 
A população que estava a assistir aquele espetáculo sem precedentes, tocada pela persistência daquele homem, iniciou um coro ensurdecedor no qual clamavam: "Dá-lhe o barco, dá-lhe o barco"44. Desconcertado o rei resolveu por fim em dar-Ihe a embarcação, mas, sem a equipagem técnica e pessoal necessária.

Ao partir em direção ao porto para recolher o barco que the era de direito, o homem não esperava já ter conquistado marinheiros. A mulher da limpeza pensou consigo que "já bastava de uma vida de limpar e lavar palácios, que tinha chegado a hora de mudar de ofícios, que lavar e limpar barcos era sua vocação verdadeira, no mar, ao menos, a água nunca lhe faltaria" ${ }^{\not 5}$.

Chegando às instalações portuárias, o homem dirigiu-se ao capitão, entregando-Ihe a recomendação real de oferecer-Ihe uma embarcação. O capitão do reino, por sua vez, intrigado confabula com o homem:

Poderás dizer-me para que queres o barco, Para ir a procura da ilha desconhecida, Já não há ilhas desconhecidas, (...), É estranho que tu, sendo homem do mar me digas isso, que já não há ilhas desconhecidas, homem da terra sou eu, e não ignoro que todas as ilhas, mesmo as conhecidas, são desconhecidas enquanto não desembarcarmos nelas. ${ }^{46}$

Estando a caravela escolhida, o homem necessitava, agora, ir em busca de sua tripulação. Neste momento é surpreendido pela mulher da limpeza a quem indaga: "E por que não estás tu no palácio do rei a limpar e a abrir portas". A mulher Ihe responde "Porque as portas que eu realmente queria já foram abertas e porque de hoje em diante só limparei barcos"47.

Deste modo, a primeira marinheira já estava escalada. Primeira e única uma vez que os outros homens "disseram que não há ilhas desconhecidas, e que, mesmo que as houvesse, não iriam eles tirar-se do sossego de seus lares e da boa vida dos barcos de carreira para se meterem em aventuras oceânicas, à procura de um impossível".

A agora maruja encorajou-lhe a partir ainda que com a tripulação reduzida entoando lição aprendida com o filósofo do rei: "Dizia que todo homem era uma ilha".

\footnotetext{
${ }^{44}$ Id. p. 19.

45 Id. p. 24.

46 Id. p. 27.

${ }^{47}$ Ibid. Trecho do diálogo retirado da página 31.
} 
Neste sentido, arremata interpretando "que é necessário sair da ilha para ver a ilha, que não nos vemos se não saímos de nós. Se não saímos de nós próprios(...)"48.

A primeira noite cai cobrindo os sonhos e esperanças daquele homem que possuía uma tripulação de uma só pessoa. Durante seu sono fantasia as aventuras que a sua caravela poderia proporcionar-lhe, singrando as águas do mar tormentoso, repleta de marinheiros e de expectativas. Nesta ilusão:

E a ilha desconhecia, perguntou o homem do leme, A ilha desconhecia é coisa que não existe, não passa duma idéia da tua cabeça, os geógrafos do rei foram ver nos mapas e declararam que ilhas por conhecer é coisa que se acabou desde há muito tempo, Deveis ter ficado na cidade, em lugar de vir atrapalhar-me a navegação, Andávamos a procura de um sítio melhor para viver e resolvemos aproveitar tua viagem, Não sois marinheiros, Nunca o fomos, Sozinho, não serei capaz de governar o barco, Pensasses nisso antes de ir pedi-lo ao rei, o mar não ensina a navegar. ${ }^{49}$

Após estes infaustos pensamentos:

acordou abraçado à mulher da limpeza, e ela a ele, confundidos os corpos, confundidos os beliches, que não se sabe se este é o de bombordo ou estibordo. Depois, mal o sol acabou de nascer, o homem e a mulher foram pintar na proa do barco, de um lado e de outro, em letras brancas, o nome que ainda faltava dar à caravela. Pela hora do meio-dia, com a maré, $\underline{A}$ llha Desconhecida fez-se enfim ao mar, à procura de si mesma. ${ }^{50}$ (sem grifo no original)

Assim exposto o itinerário traçado pelo homem do leme, entre seu sonho e vontade de buscar a ilha desconhecida e a efetivação por meio do instrumental barco - fornecido pelo rei, este deverá nos servir de paradigma para a singela caminhada que também objetivamos singrar.

Impende-se, destarte, buscar mecanismos de aproximação ("barco") entre o discurso teórico e a proteção efetiva dos direitos humanos e dos direitos fundamentais (nossa "ilha desconhecida").

Bem como no conto de Saramago em que a idéia da ilha desconhecida se desvela em uma dúplice concepção: na esfera individual (dentro do homem) e na

\footnotetext{
48 Ibid. Trecho retirado da página 41.

49 Ibid. p. 57.

50 Ibid. p. 62.
} 
social (nos arquipélagos), a proteção dos direitos humanos e fundamentais também se desdobra neste dúplice viés: na ação individual como exercício de cidadania e na seara social por meio da doutrina, legislação e jurisprudência.

Em que pese a grande relevância que a atuação individual possua nesta matéria, seu estudo aqui não nos compete uma vez que as vicissitudes e motivações internas, racionais e irracionais de cada sujeito ficam além das possibilidades de análise da presente autora.

É justamente na dimensão coletiva que essa aproximação se edificará, com o intento de ruptura do conformismo e da monotonia das rotas e itinerários análogos já riscados pelos geógrafos do reino, no que diz respeito aos direitos humanos e fundamentais.

Nesta singra, tendo como horizonte a realização concreta desses direitos, faz-se necessária a atuação da doutrina, recolhendo também os frutos da legislação e da jurisprudência, em busca de instrumentos de aproximação do discurso jurídico e da prática efetiva - porto melhor para ancorarmos nossos sonhos e reflexões.

Eis o desafio que nos cabe para o porvir. Destarte, navegando pelas águas das narrativas emancipatórias anteriormente delineadas, é imperioso o repensar do instrumental teórico já disposto em matéria de direitos humanos e de direitos fundamentais (ou seja, o barco que nos foi 'legado') para então lançarmo-nos ao mar em busca da mitigação desse fosso abissal, com a única certeza de que não existem soluções prontas a serem encontradas.

\section{NOTAS DERRADEIRAS}

Percorrido o caminho proposto, o trabalho aponta para as conclusões que emergem do artigo.

Pensar o direito através das lentes literárias fornece um aporte crítico e emancipador do real uma vez que rompe com a monotonia do discurso jurídico dogmático hermético. Nesta toada é que esta reflexão abrolha da interlocução entre o direito e a literatura. Admitir esta interpenetração pressupõe uma abertura da ciência jurídica, paradoxalmente necessária para preencher a frincha subsistente entre a teoria e prática dos direitos humanos e fundamentais. 
Verifica-se que é necessária uma nova teoria acerca destes direitos. A reflexão acerca desta nova teoria e dos mecanismos para alcançá-la, todavia, não pode incorrer, sob o risco contraditório do abstracionismo, em discursos ou soluções praticamente incapacitados.

A luta do homem do leme, no conto de Saramago, vivifica esta pesquisa: o barco conquistado (neste caso, os barcos) para trilhar a rota entre o tido (sonho) e o almejado (ilha desconhecida) deve ter, concomitantemente, a solidez necessária para navegar pelos mares doutrinários, mas também, o comprometimento ético necessário para enfrentar as tormentas que se formam nos oceanos de experiências práticas dos direitos humanos e fundamentais.

Subscrevemos, assim, lição necessária que bem sintetiza e subsidia as idéias do presente projeto, para seguir em frente:

Para salvar la vida de las mayorías urge liberar los derechos humanos. Liberarlos del formalismo jurídico que no sólo ha mostrado ser funcional al sistema de muerte, sino que desarrolla hoy en día una utopía de ciudadanía del mundo cosmopolita a partir de un imaginário jurídico de derechos humanos como ley planetaria. No se trata de rechazar la juridicidad actual fruto de transcendentales luchas emancipatorias. Se trata de liberarla del utopismo institucional que se ha constituido a partir de ella, y que hoy es instrumento de un poder imperial occidental. Esto significa eliminar la visión de los derechos humanos como proyecto de sociedad a construir y legitima cualquer medio para su materialización. Los derechos humanos como juridicidad son recuperables solo con apoyo a las luchas de resistencia de las victimas y no como instrumento de legitimación de ningun orden social o institucional. ${ }^{51}$

${ }^{51}$ Para salvar a vida das maiorias urge libertar os diretos humanos. Libertá-los do formalismo jurídico que não só se mostrou funcional ao sistema de morte, mas que desenvolve hoje em dia uma utopia de cidadania do mundo cosmopolita a partir de um imaginário jurídico de direitos humanos como lei planetária. Não se trata de rechaçar a juridicidade atual fruto de transcendentais lutas emancipatórias. Trata-se de liberá-la do utopismo institucional que se construiu a partir dela, e que hoje é um instrumento do poder imperial ocidental. Isto significa eliminar a visão dos direitos humanos como projeto de sociedade a construir e legitimar quaisquer meios para sua materialização. Os direitos humanos como juridicidade são apenas recuperáveis com o apoio às lutas de resistência das vítimas e não como instrumento de legitimação de nenhuma ordem social ou institucional (Tradução livre).GUTIÉRREZ, G. Globalización y Liberación de los Derechos Humanos. In: FLORES, J. H. EI vuelo de Anteo: derechos humanos y critica de la razón liberal. Bilbao: Desclée, 2000. p. 198. 


\section{BIBLIOGRAFIA}

ALEXY, R. Teoria de Los Derechos Fundamentales. Ernesto Grazón Valdés (trad.). Madrid: Centro de Estudios Constitucionales, 1993.

ANTUNES ROCHA. C. L. O Princípio da Dignidade da Pessoa Humana e a Exclusão Social. Revista Interesse Público, São Paulo, nº 4, out/dez 1999.

ARAÚJO, L. A. D.; NUNES JÚNIOR, V. S. Curso de Direito Constitucional. São Paulo: Saraiva, 2001.

AVELAS NUNES, A. J. Neoliberalismo e Direitos Humanos. Rio de Janeiro: Renovar, 2003.

BARROZO, L. R. O Direito Constitucional e a Efetividade de suas Normas. Rio de Janeiro: Renovar, 2002.

BOBBIO, N. A Era dos Direitos. São Paulo: Editora Campus, 1992.

BONAVIDES, P. Curso de Direito Constitucional. São Paulo: Editora Malheiros, 1997.

CANOTILHO, J. J. G. Direito Constitucional e Teoria da Constituição. Coimbra: Almedina, 2002.

CASTRO, R. O. de. Direitos Humanos: conquistas e desafios. Brasília: Letraviva, 1999.

COMPARATO, F. K. A Afirmação Histórica dos Direitos Humanos. 2 ed. São Paulo: Saraiva, 2001.

DERRIDA, J. Acts of literature. New York and London : Routledge, 1992.

DORA, D. D. Direito e Mudança Social. Rio de Janeiro: Renovar, 2003.

DWORKIN, R. Taking rights seriously. Cambridge: Harvard University Press, 1982.

ELLACURÍA, I. Los derechos humanos fundamentales y su limitación legal y política. San Salvador: UCA, 1969.

FLORES, J. H. (coord.). El Vuelo de Anteo: derechos humanos y crítica da la razón liberal. Bilbao: Desclée, 2000.

FRUTOS, J. S. de. Ella curia y los Derechos Humanos. Bilbao: Desclée, 1998.

KANT, Immanuel. Fundamentação da Metafísica dos Costumes. In: Crítica da Razão Pura e outros Textos. 1 ed. São Paulo: Abril Cultural S/A,1974.

LUÑO, A. P. Los Derechos Fundamentales. Madrid: Tecnos, 2004.

MATURANA, H.; VARELA, F. A árvore do conhecimento: as bases biológicas da compreensão humana. São Paulo: Palas Athena, 2001.

MELLO, C. D. de A. Arquivos de Direitos Humanos. Rio de Janeiro: Renovar, 1999. 
MIRANDA, J. Direitos Fundamentais: introdução geral. Lisboa: s.n., 1999.

MORAWETZ, T. Law and Literature. In: PATERSON, D. A Companion to Philosophy of Law and Legal Theory. USA: Blackwell, 1999.

NUSSBAUM, M. Poetic Justice: The literary imagination and public life. Boston: Beacon Press, 1997. OST, F. Raconter la Loi. Paris: Odile-Jacob, 2004.

PIOVESAN, Flávia. Temas de Direitos Humanos. São Paulo: Max Limonad, 2003.

POSNER, R. Law and literature. Cambridge, Mass. and London : Harvard University Press, 1998.

PRIETO, F.; THEOTONIO, V. Los Derechos Humanos: una reflexión interdisciplinar. Córdoba: ETEA, 1995.

SARAMAGO, J. Conto da ilha desconhecida. São Paulo: Cia das letras. S/d.

SARLET, I. W. A eficácia dos direitos fundamentais. Porto Alegre: Livraria do Advogado, 1998.

Constituição, Direitos Fundamentais e Direito Privado. Porto Alegre: Livraria do Advogado, 2003.

SILVA, J. A. Curso de Direito Constitucional Positivo. 20 ed. São Paulo: Malheiros, 2001. 